\title{
Laser hardening of copper-iron pseudoalloy
}

\author{
E. A. Morozova , T. R. Ablyaz ${ }^{\text {a }, ~ K . ~ R . ~ M u r a t o v a, ~ E . ~ S . ~ S h l y k o v ~ a n d ~ E . ~ V . ~ S m o l e n t s e v ~}{ }^{\text {* }}$
}

${ }^{a}$ Perm National Research Polytechnic University, Perm, Russian Federation

${ }^{b}$ Voronezh State Technical University, Voronezh, Russian Federation

\begin{tabular}{l}
\hline A R T I C L EI N F O \\
\hline Article history: \\
Received 14 September 2019 \\
Accepted 31 October 2019 \\
Available online \\
31 October 2019 \\
\hline Keywords: \\
Laser heat treatment \\
Powder metallurgy \\
Steel-copper pseudoalloy \\
Microstructure \\
Microhardness \\
Abrasive wear
\end{tabular}

\section{Introduction}

Laser surface hardening treatment of alloys applied in mechanic engineering offers numerous challenges. Such treatment provides local heating with minimum deformations if any and cooling due to heat removal into the bulk of material, generally without application of cooling media. High rates of heating and cooling amounting to $104 \ldots 106^{\circ} \mathrm{C} / \mathrm{s}$ leads to obtaining of superior physico-mechanical properties of surface layers (Ivanov et al., 2011; Tolochko., 1995). High-power fiber lasers are applied more and more widely in various technologies, replacing all other types of lasers (Turichin et al., 2012; Goia and Lima 2011). This is related with their high efficiency, high reliability and lower dimensions (Kraposhin et al., 1990). However, the results of laser heat treatment (LHT), obtained previously within application of CO2-lasers, should be revised in tests with fiber lasers (Kraposhin and Kraposhina 1989). The main difference is the shorter wavelength of fiber lasers in comparison with CO2-laser (1.07 $\mu \mathrm{m}$ and $10.6 \mu \mathrm{m}$, respectively) and thus significantly higher level of radiation absorption by steel surfaces. This in particular eliminates necessity to use surfaces which enhance absorption. The efficiency of fiber lasers

\footnotetext{
* Corresponding author. Tel:+98-54-31232024

E-mail addresses: kruspert@mail.ru $\quad$ (E. V. Smolentsev)
}

(C) 2020 Growing Science Ltd. All rights reserved. doi: $10.5267 /$ j.esm.2019.10.006

\begin{abstract}
The purpose of the study is to improve the performance characteristics of powder pseudo-alloy materials using surface heat treatment. Such materials have unique properties, for example, selferosion resistance. The disadvantage of powder pseudo-alloys is their relatively low strength. The per describes the method of experimental research, describes the method of obtaining powder microstructure and microhardness of the surface layer of steel-copper powder pseudo-alloy after (LHT) of a continuous-wave fiber laser with a maximum power of $1 \mathrm{~kW}$ are hardened layer is evaluated. It is revealed that the partial melting region in which melting occurs in the volumes of the fusible component (copper) in the initial structure and contacting segments of steel matrix is formed in the material in addition to the total melting zone. Then the quenching best samples in the volume of martensite, which is formed in perlite colonies of the initial steelcopper material.
\end{abstract}


is $25 \%$, which is by 2.5-3 times higher than that of serial CO2-lasers, whereas the difference in total energy efficiency of quenching by means of fiber lasers is even higher (Kraposhin and Kraposhina 1989). Herewith, great attention is still attracted by the articles where CO2-lasers have been applied for establishment of main relationships of laser quenching of steels, for instance, (Babu et al., 2012; Gilev et al., 2014). Only specific treatment modes should be adjusted.

Analysis of published materials demonstrates that the most meaningful parameters, which influence on the processes occurring within laser treatment as well as on the properties of treated materials, are laser power, its density and the speed of laser beam travelling. The power distribution and shape of laser beam, wavelength and laser type, surface roughness, properties and structure of treated material are also of great importance. Wear resistance of steels after laser treatment depends on distribution of residual stresses. The studies are usually carried out on model samples of simple shape, these are usually plates. It is possible to assume that a more complicated configuration of treated items can lead to significantly more complicated pattern stress distribution.

Despite numerous works devoted to laser heat treatment (LHT) of materials, the influence of LHT on individual classes of materials, such as steel-- copper pseudo-alloys produced by the methods of powder metallurgy, has not been studied in details. The works on laser treatments of powder steel are usually aimed decrease in porosity by means of melting of surface layers of porous materials or at cladding of wear resistance compositions (Popov., 2009; Postnikov et al. 1991; Kannatey-Asibu, 2009). In addition, in order to develop practical application of LHT in mechanical engineering it is necessary to perform studies on items with more complicated configuration. This work is devoted to LHT of steel-copper pseudo-alloy with high volumetric content of steel constituent, thus, the experience with LHT steels can be used in the course of the studies. In the work performed by Brytan and Dobrzański (2011) the grade U9 and U10 steels have been quenched using $1.5 \mathrm{~kW} \mathrm{CO2-laser} \mathrm{with} \mathrm{the} \mathrm{speed} \mathrm{of} 0.75 \mathrm{~m} / \mathrm{min}(12.5$ $\mathrm{mm} / \mathrm{s}$ ) up to the hardness of about 1000 and $1100 \mathrm{HV}$. Similar results were many times obtained by other researchers, hence, according to the data (Astapchik et al., 1991) carbon steels can be treated by laser both with and without melting. Herewith, the microhardness in the melting area increases with carbon content (up to 0.8-1.0 \%) and reaches $1000 \mathrm{HV}$ for steel, grade U9, which is by 100-150 HV higher than within conventional quenching.

Some authors (Kraposhin., 1994; Gilev et al., 2014) believe that it is difficult to forecast structural modification in steel or cast iron of this chemical composition as a consequence of modification of even single parameter of laser heating. It can be determined only experimentally, since the influence of the parameters on heating temperature, austenite grain sizes and phase composition after quenching is not unique. Alongside with that, the calculated parameters are known, which facilitate estimation of heating temperature and dimensions of areas of laser impact. For instance, the portion of residual austenite correlates with maximum temperature, which is to the parameter

$$
\frac{P}{\lambda d}\left(\frac{\alpha}{d v}\right)^{0.4}
$$

where $\mathrm{P}$ is the power, $v$ is the travel speed, $\lambda, \alpha$ are the thermal conductivity and temperature conductivity of the material, respectively, $d$ is the spot diameter. The sizes of the hardened area for steel 45 correlate with the parameter:

$$
P /(d v)^{0.4} \text {. }
$$

The materials of steel-copper pseudo-alloy type have not been exposed to LHT previously except for our work (Ivanov et al., 2011). The most similar study of rapid heat treatment of such composition is the work (Grigoryants et al., 1987), which studied steel 45 after implementation of copper into surface by explosive treatment of copper wire within passing of current with subsequent electron beam remelting of 
the surface. The microhardness of $1000 \mathrm{HV}$ was obtained in the layer of material with $15 \mathrm{vol} \%$ of disperse depositions of copper.

\section{Experimental part}

The composition of the considered material is as follows: $1 \% \mathrm{C}, 15 \% \mathrm{Cu}$, the remainder is iron. $\mathrm{A}$ part of samples was presented by components (diffusers) of steps of multistage submersible pumps, Company Novomet-Perm, produced by the methods of powder metallurgy. Model samples of the same composition and structure had the shape and dimensions similar to those of annular collars on upper disks of diffusers, which together with the washers of working wheels form the friction couple of axial bearings of the step. The model samples were in the form of annular collars with the width of $4.5 \mathrm{~mm}$, outer diameter of $49 \mathrm{~mm}$ and height of $\sim 2.5 \mathrm{~mm}$, on a disk with the width of $2.5 \mathrm{~mm}$ made of the same material. The workpieces were produced by conventional methods of powder metallurgy: pressing of mixture of powdered iron and graphite and sintering in the environment of dissociated ammonium with simultaneous impregnation with copper. Their structure consists mainly of lamellar pearlite of various dispersion rates, copper inclusions, and minor amount of ferrite, Fig. 1. The hardness of the material after sintering is $70-100 \mathrm{HRB}$, the microhardness is usually in the range of $250-300 \mathrm{HV}$. The annular collars on the samples for LHT were obtained by machining of preliminary sintered workpieces. The initial surface roughness $\mathrm{Ra}$ of the samples after machining were measured using am Abris-PM7 profile testing machine, and within measurement along the cutting direction was $<0.14 \mu \mathrm{m}$, and $<1 \mu \mathrm{m}$ in transverse direction. Laser heat treatment was performed using an OPTOMEC LENS 850-R system with YLR-1000 IPG Photonics fiber laser, with the spot of round cross section and the Gaussian distribution of power. The parameters of laser treatment were selected with consideration for the data (Shiue and Chen 1992) as reference. The following parameters were set in the experimental plan: laser power P, power density I ( $I=\frac{W}{S}, S=\pi d^{2}$, where $\mathrm{d}$ is the spot diameter of laser beam in the point of impingement with treated surface) the travel speed of laser beam along the surface $v$.

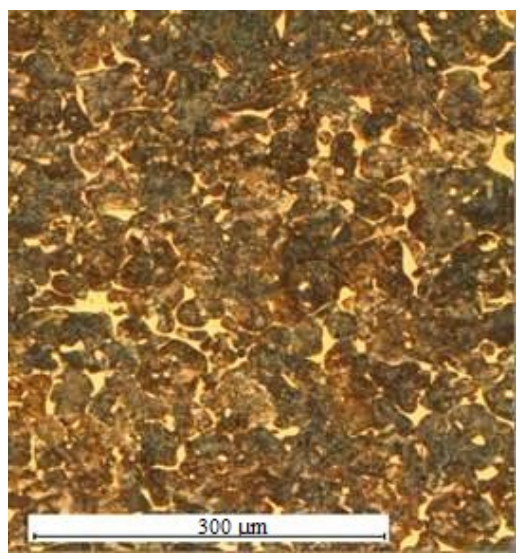

Fig. 1 Microstructure of the considered powdered steel-copper pseudo-alloy in sintered state.

The spot size was controlled by variation of the distance $\mathrm{Z}$ from the laser focal plane to the treated surface. In order to calculate $Z$ the equation (Brytan et al., 2011; Safonov, 1996) was used which determines the current radius $\omega(Z)$ as a function of position of sample surface with regard to the focal plane:

$$
\omega(Z)=\varpi_{0}\left[1+\left(\frac{M^{2} \lambda \cdot Z}{\pi \cdot \varpi_{0}^{2}}\right)^{2}\right]^{1 / 2},
$$


where $\omega(\mathrm{Z})=\mathrm{d} / 2, \mathrm{Z}$ is the distance from focal plane, $\omega_{0}$ - is the minimum beam radius (radius in focal plane), $\mathrm{M}^{2}$ is the beam quality factor, $\lambda$ is the laser wavelength. The following equation was also applied (Qiu et al., 2011):

$$
M^{2}=\frac{B P P}{\lambda / \pi}
$$

where the parameter BPP (Beam Parameter Product) was given in the specification of the laser, BPP = 2.5-2.7 $\mathrm{mm} * \mathrm{mrad}$. More detailed discussion of the beam shape of fiber laser is given elsewhere (Gilev et al., 2012). The treatment was performed by single passes in the environment of high-pure argon. The details of laser treatment are summarized in Table 1 . The microhardness was measured using a Durascan 70 automatic microhardness tester at the load of $50 \mathrm{~g}$ with increment of $50 \mu \mathrm{m}$ along the line perpendicular to sample surface in the middle of laser path. When a planned impression coincided with copper inclusion or visible from the surface defect, the indention point was displaced. The microstructure after laser heat treatment was studied using an GX-51 microscope at magnification of 50-1000x. The surface state was analyzed using an MBC-10 microscope. The microstructure was revealed using $4 \%$ solution of $\mathrm{HNO}_{3}$. The depth of $3 /$ heat-affected zone (HAZ) was determined as the distance to the line crossing at the level of $700 \mathrm{HV}$ with the plot of microhardness distribution $\left(\mathrm{L}_{\mathrm{HAZ}}{ }^{1}\right)$, as well as the distance from the surface to the boundary of transition to permanent initial structure of material $\left(\mathrm{L}_{\mathrm{HAZ}} \mathrm{Z}^{2}\right)$. In order to estimate the effect of improvement of tribological properties as a consequence of laser quenching of one of the surfaces of axial bearings bench-scale comparative experiments of multistage assemblies in water environment with abrasive particles were carried out.

Table 1. Conditions and results of laser treatment on annular collars

\begin{tabular}{|c|c|c|c|c|c|c|c|c|}
\hline $\begin{array}{c}\text { Experiment } \\
\# \\
\end{array}$ & $\begin{array}{c}\mathrm{P}, \\
\mathrm{kW}\end{array}$ & $\begin{array}{c}(\mathrm{P} / \mathrm{S}), \\
\left(\mathrm{kW} / \mathrm{cm}^{2}\right)\end{array}$ & $\begin{array}{c}\mathrm{d}, \\
\mathrm{mm}\end{array}$ & $\begin{array}{c}\mathrm{V}, \\
\mathrm{cm} / \mathrm{s}\end{array}$ & $\begin{array}{c}\text { LMEL, } \\
\mu \mathrm{m}\end{array}$ & $\begin{array}{c}\mathrm{LHAZ}^{1} \\
\mathrm{~mm}\end{array}$ & $\begin{array}{c}\mathrm{LHAZ}^{2}, \\
\mathrm{~mm}\end{array}$ & $\mathrm{HV}^{* *}$ \\
\hline 1 & 0,9 & 16 & 2,68 & 1,2 & - & 0,94 & & 764 \\
\hline 2 & 0,9 & 8 & 3,79 & 1,0 & - & 1,1 & & 760 \\
\hline 3 & 0,8 & 16 & 2,52 & 1,0 & - & 0,64 & 0,83 & 894 \\
\hline 4 & 0,8 & 8 & 3,57 & 1,2 & - & 0,91 & & 811 \\
\hline 5 & 0,7 & 16 & 2,36 & 1,2 & - & 0,62 & & 928 \\
\hline 6 & 0,7 & 8 & 3,34 & 1,0 & - & 0,69 & & 934 \\
\hline 7 & 0,6 & 16 & 2,19 & 1,0 & - & 0,34 & & 854 \\
\hline 8 & 0,6 & 8 & 3,09 & 1,2 & - & 0,77 & & 883 \\
\hline 9 & 1,0 & 12 & 3,2 & 1,2 & 139 & 0,92 & 0,98 & 807 \\
\hline 10 & 1,0 & 12 & 3,2 & 0,8 & 287 & 1,21 & 1,36 & 765 \\
\hline 11 & 1,0 & 8 & 3,99 & 1,2 & 90 & 1,02 & 0,96 & 810 \\
\hline 12 & 1,0 & 8 & 3,99 & 0,8 & 170 & 1,25 & 1,35 & 800 \\
\hline
\end{tabular}

$\mathrm{L}_{\mathrm{MEL}}$ - the depth of complete melting

* $\mathrm{L}_{\mathrm{HAZ}}{ }^{1}$ - the depth of layer with microhardness higher than $700 \mathrm{HV}$

$* \mathrm{~L}_{\mathrm{HAZ}}{ }^{2}$ - the depth to the boundary with pearlite structure

** - average value of microhardness according to the measurements in the range of 0-350 $\mu \mathrm{m}$

\section{Results and discussion}

\subsection{Modes of laser heat treatment}

The modes and results of LHT are summarized in Table 1. Average microhardness of surface layer at the depth of up to $350 \mu \mathrm{m}$ varies in the range of $765-934 \mathrm{HV}$, the depth of the layer with high microhardness $\mathrm{LHAZ}^{1}$ is in the range of $0.34-1.25 \mathrm{~mm}$. Fig. 2 illustrates the microstructure (a), microhardness distribution in the surface layer of the considered material after laser treatment (b) according to the following mode: $\mathrm{P}=1 \mathrm{~kW}, \mathrm{P} / \mathrm{S}=8 \mathrm{~kW} / \mathrm{cm} 2, \mathrm{~d}=3.99 \mathrm{~mm}, \mathrm{v}=12 \mathrm{~mm} / \mathrm{s}$ (sample \#11). The hardness measured on the surface of annular collar by Rockwell is $55.5 \mathrm{HRC}$. 

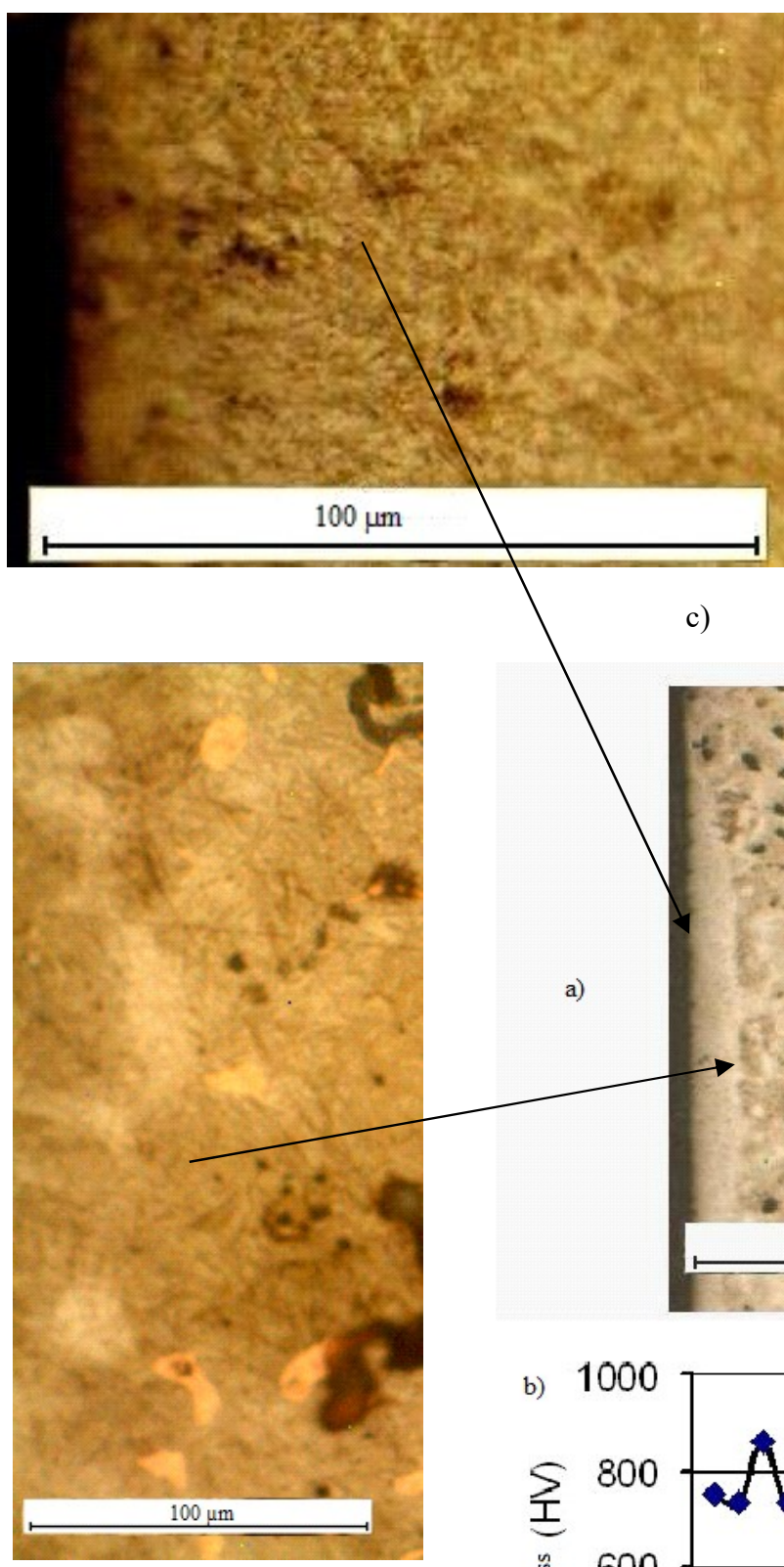

d)

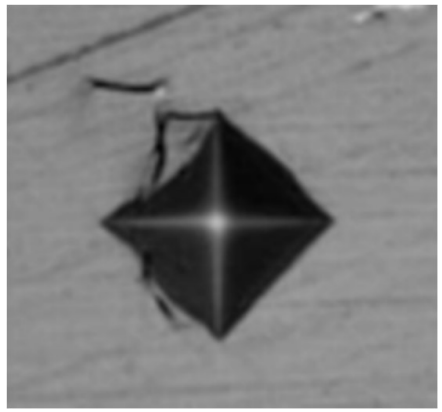

f)

c)

a)

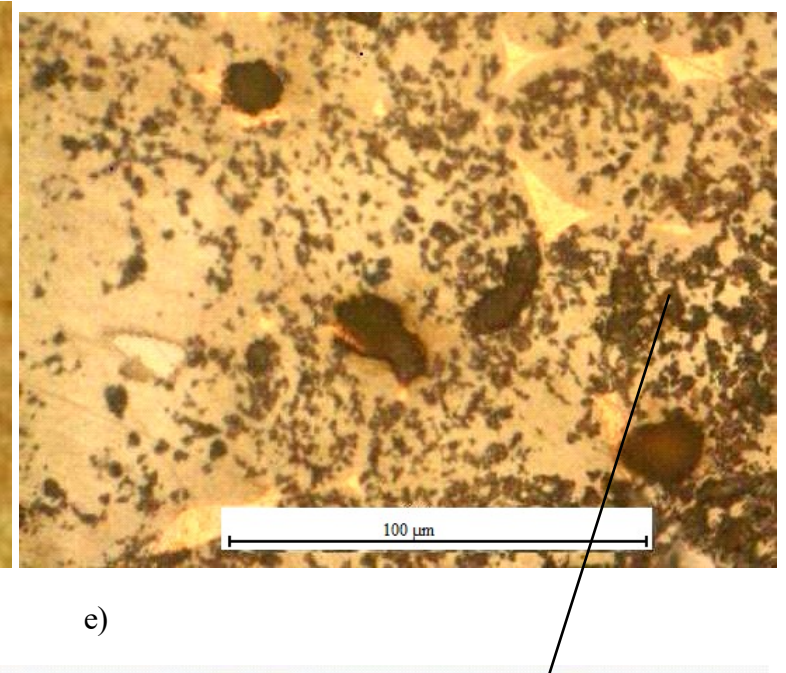

e)
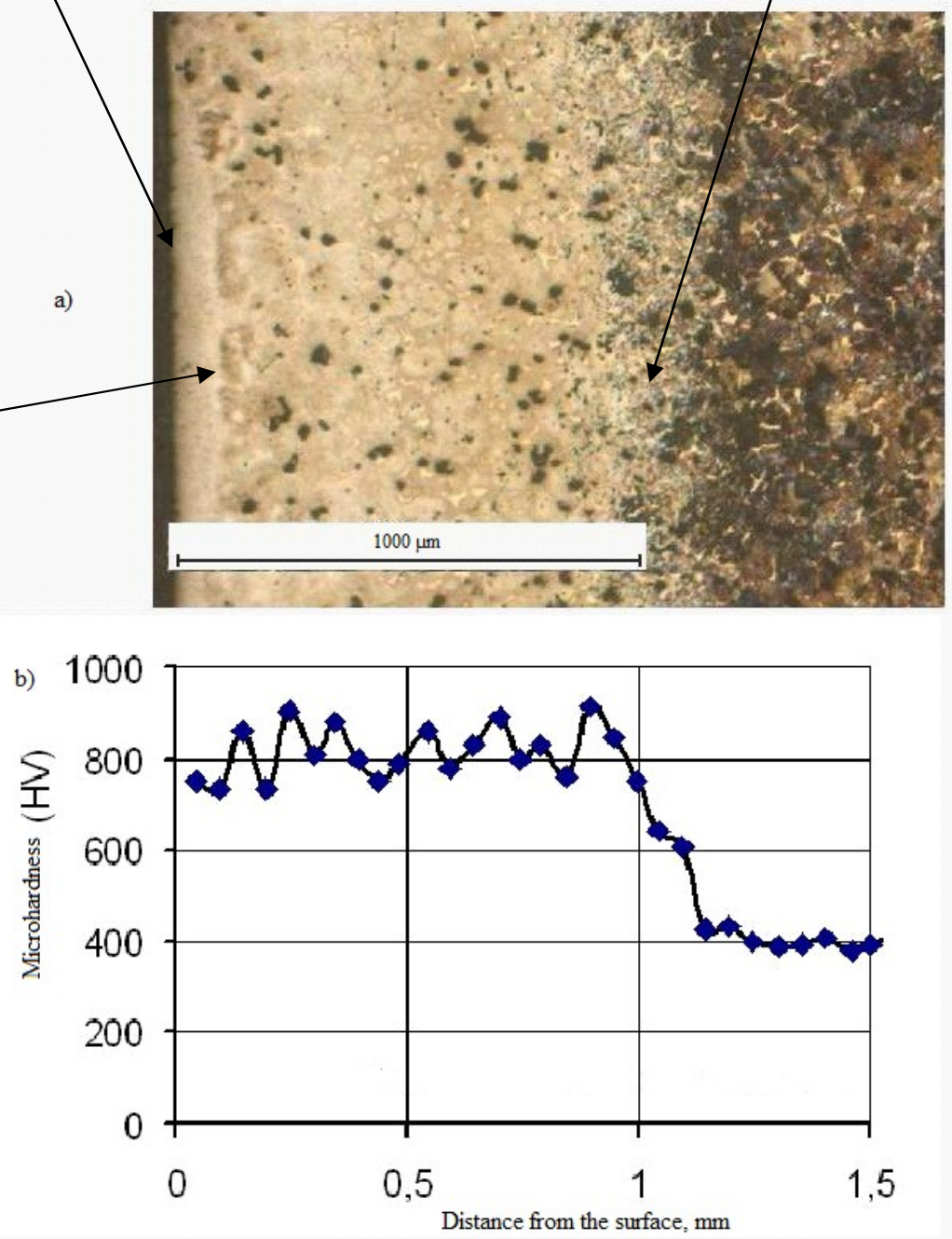

Fig. 2. Microstructure after LHT \#11: a - cross-section of laser impact zone, general view, $b$ - microstructure distribution in depth, $\mathrm{c}$ - melting zone structure, $\mathrm{d}$ - spot-like structure in the zone of complete fusion, $\mathrm{e}$ - structure of transition from solid state quenching zone to base, $\mathrm{f}-$ and example of impression with subsurface structure defect. 
It is possible to highlight at least four zones with different microstructure, Fig. 2a, which agree well with the plot of microhardness distribution in depth, Fig. 2b. Zone I with thickness of about $90 \mu \mathrm{m}$ is the zone of complete melting, where, probably, the disperse mixture of quenched steel and copper deposits is generated. The structure of the zone of complete melting in optical microscope can hardly be observed, Fig. 2c. The elements of dendrite structure and fine-needled martensite overlap. Partial melting occurs in Zone II, namely: melting near areas of copper constituent of initial structure, where, as a rule, it is possible to observe curing of pores due to migration of liquid copper. Zone II is characterized with heterogeneous etching. The areas near initial copper inclusions, which pass into melt within laser treatment, are enriched with copper, they are bright, as Zone I. The areas located distantly from copper inclusions and which were not melted, or the residence time of which in melted stare was shorter, are darker. As a consequence, the spot-like structure with smooth transitions between dark and bright areas is generated, Fig. $2 \mathrm{~d}$.

Zone III, propagated in depth of from 150 to $1000 \mu \mathrm{m}$, is the zone of martensite quenching from solid state, it is characterized with high hardness. The structure of this material contains defects: pores and copper inclusions, which impacts on microhardness distribution in the form of scattered results of measurements. As a rule, the gaps on the microhardness curve are associated with existence of hidden defects under initial defect-free surface (pores or cracks), which are exposed during indentation, Fig. $2 \mathrm{f}$. Zone IV is the transient zone with the depth of about $150 \mu \mathrm{m}$, where the structure is visible modified within laser quenching, however, the heating temperature and cooling rates in this zone are not sufficient for martensite generation in overall bulk, the hardness in this zone gradually decreases with martensite content in the structure to the level of core hardness (Zone V). The structure of Zone IV consists of martensite and areas of troostite, which can be observed as dark spots. The content of troostite increases with the distance from the surface, Fig. 2e. The remaining bulk, Zone V, is actually unmodified structure, which consists mainly of pearlite but with slightly increased microhardness ( $400 \mathrm{HV}$ ) in comparison with microhardness of material in initial state (250-300 HV). It should be mentioned that the results in Fig. 2 is one of the most successful, since in this experiment the hardening to the depth of $1 \mathrm{~mm}$ was accompanied with generation of finely melted layer at minimum height of generated relief on the surface, Fig. 3a. Herewith, it should be understood that this result is a consequence of combination of LHT modes with certain configuration of treated sample. Even slight modification of typical size of a sample can lead to another result, differing from that illustrated in Figs. 2 and 3a.

\subsection{The influence of configuration of treated samples}

Fig. 3 illustrates the influence of configuration and sizes of laser treated item. The samples differ with slight variation of height of the annular collars, 2.0 and $2.5 \mathrm{~mm}$.

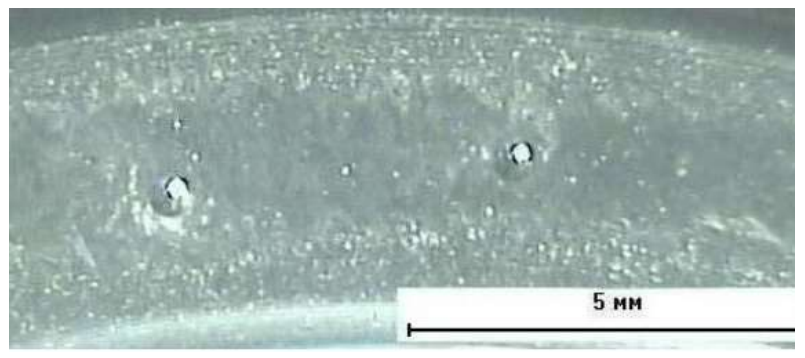

(a)

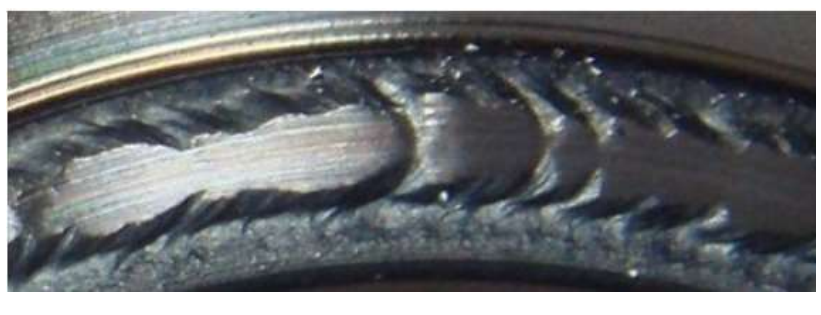

(b)

Fig. 3. Surface of annular collar after LTT according to mode \#11: a - collar height $2.0 \mathrm{~mm}, \mathrm{~b}$ - collar height $2.5 \mathrm{~mm}$ (an attempt of machining of the sample).

A melting strip with sufficiently smooth surface with the width of $\sim 1.5 \mathrm{~mm}$ can be seen on the sample surface with the height of annular collar of $2.0 \mathrm{~mm}$ after LHT (Fig. 3a), which is related with small 
melting depth. The results of studies of this sample are illustrated in Fig. 2. Strips with small relief are observed on both sides. These are the areas of partial melting, where steel frame retains its consistency, and the areas near copper inclusions are melted. Figure $3 \mathrm{~b}$ illustrates the sample surface with the height of annular collar of $2.5 \mathrm{~mm}$ after LHT according to the same mode. Increase in the collar height by $20 \%$ lead to significant complication of heat removal from the treated surface and provided deeper melting of the surface layer with generation of deep relief. The highest microhardness of about $1000 \mathrm{HV}$ was obtained in the layers at the depth of about $0.4 \mathrm{~mm}$ in samples \#3 and \#6, as well as in sample \#8. The respective properties of samples \#5 and \#7 are close to them. All they are characterized with comparatively low depth of high hardness zone. The graph (Fig. 4) shows the dependence of microhardness on the depth of the hardened layer, and also approximate the curve of the 2nd order.

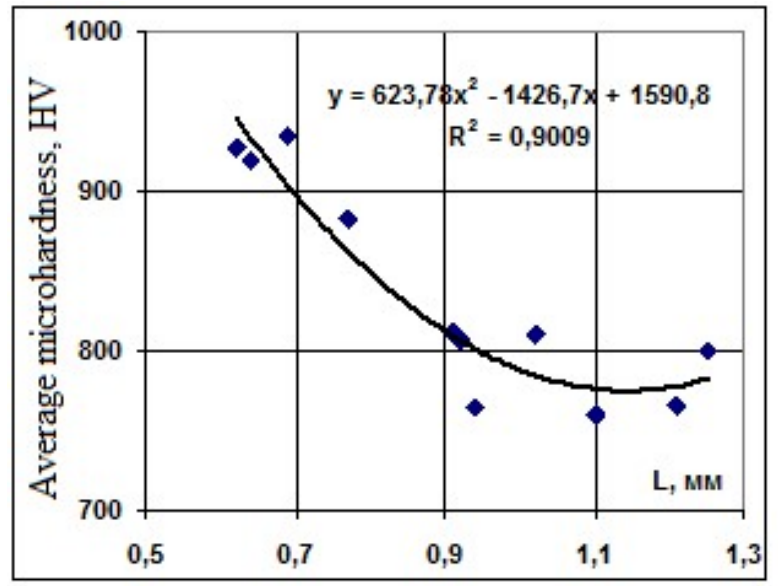

Fig.4. Approximation of surface layer microhardness as a function of depth of hardened zone L by quadratic polynomial.

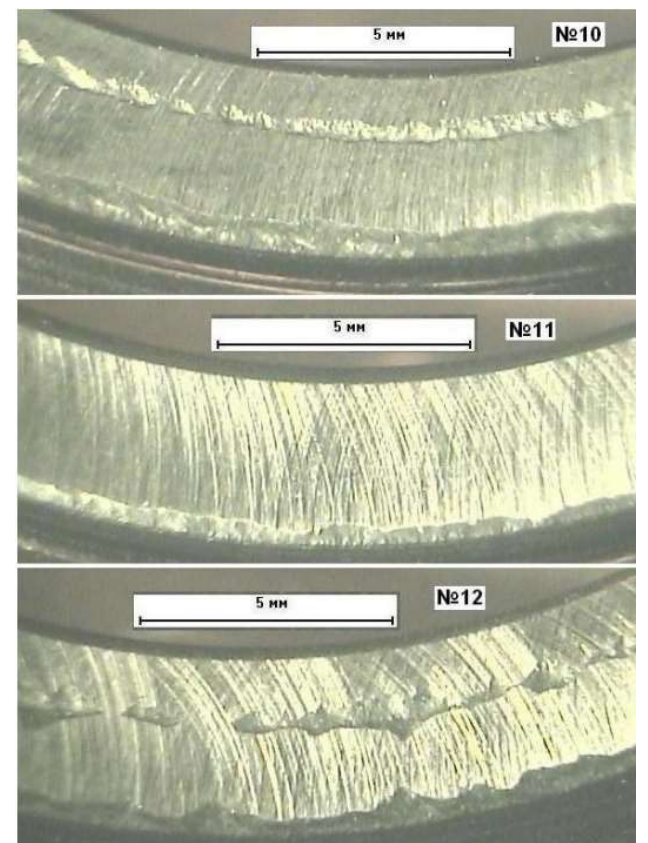

Fig. 5. Surface view of cylindrical collars after LTT according to various modes and subsequent polishing with diamond abrasive tool.

Taking into account that within LHT with melting the surface roughness increases (Ivanov et al., 2011). In this work possibilities of various types of machining were tested. Satisfactory result was obtained only with polishing, which was performed by a D91 diamond polishing tool (Strauss Co). 
According to the catalogue of the company the grit size in this tool is $90-75 \mu \mathrm{m}$. The tool rotation speed is $20000 \mathrm{rpm}$, the sample rotation speed is $200 \mathrm{rpm}$, and the depth of takeoff per one pass is $0.02 \mathrm{~mm}$. Fig. 5 illustrates the view of surface of annular collars after LHT according to various modes and polishing. It can be seen that on the samples treated according to modes \#10 and \#12 the surface after polishing contains grooves. Moreover, the depth and width of the grooves on sample \#12 periodically vary in the path. Sample \#11 contains only traces of such destructions on outer edge of the collar. Comparison of the visible image after polishing with the sizes of laser spot and sizes of melting zones makes it possible to conclude that the grooves are generated in the places of residual tensile stresses. More distinct grooves are generated during polishing at existence of deep melting zones. Therefore, generation of such grooves within polishing is an indicator of places of high tensile stresses. It should be mentioned that at low depths of melting zones the distributions of residual stresses are more favorable. The highest thermal stresses are generated in the vicinity of melting zones, which is in agreement with the data (Lisenkov et al., 2013) on possibility of cracking in these zones already at the LHT stage. It can be assumed that during LHT with melting of upper surface of narrow annular collars the distribution of stresses differs in comparison with similar treatment of the plates with the sizes significantly exceeding the width of laser impact runs.

\subsection{Metallographic analysis of the obtained samples}

Metallographic studies revealed cracking at the interface of melting zone in the sample treated according to mode 12, Fig. 6 . The laser run was displaced from the center. The cracks are generated on the surface of melting run, moreover, on that side of the run which is located nearly in the center of annular collar. On the other hand, near collar edge thermal stresses are lower and cracking does not occur. It is also possible to highlight asymmetry of the zone of complete melting, which is visible on etched polished slice, Fig. 6a, and cumulative zone of complete and partial melting, which is visible on nonetched polished slice in the form of a zone without pores, Fig. 6 b.

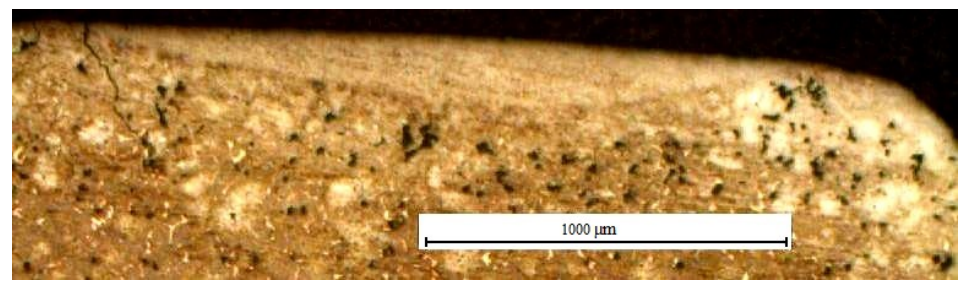

a

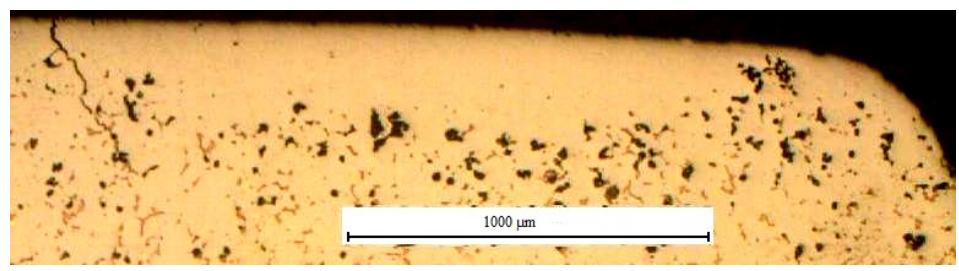

b

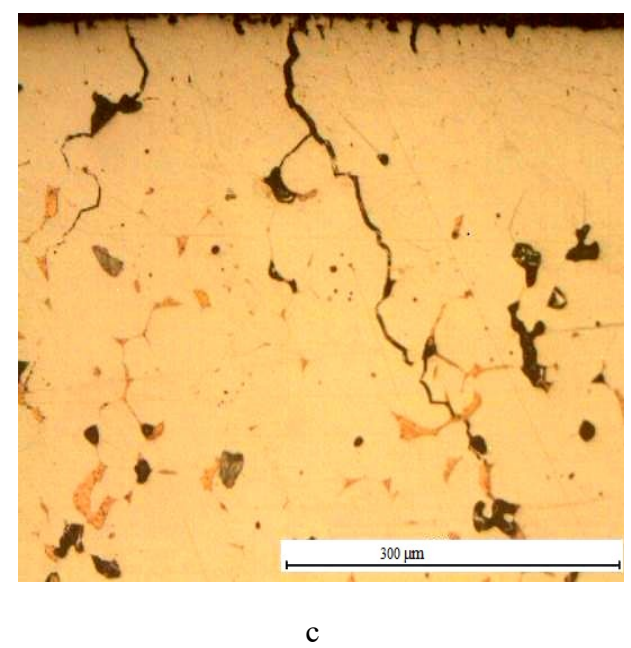

C

Fig. 6. Structure of the laser impact zone in a sample treated according to mode $\# 12$ : $a$ - etched; b - not etched; $c$ - cracks in the region of melting zone interface.

This asymmetry is a consequence of displacement of travel path of central part of laser beam from central line of the collar. Heat removal from the right hand part of irradiated zone in this case is hindered due to closeness of the right hand edge of the collar, therefore, the deepest part of the melting zone is displaced to the right. The path of crack propagation passes mainly along the grain boundaries (interstitial contacts), pores and copper inclusions, Fig. 6c. 


\subsection{Application of the obtained results}

The results of comparative bench-scale tests of the steps after LHT and regular ones are illustrated in Fig. 7. The tests \#9-12 from Table 1 were performed repeatedly on diffusers. The standard design includes the friction couple consisting of regular (thermally untreated) steel-copper pseudo-alloy and carbonite, which is an enforced plastic, usually applied in the step designs. Washers made of enforced rubber were applied in combination with quenched diffusers. According to the experimental results the wear of carbonite washers was $2 \mathrm{~mm}$, no wear of rubber washers was detected.

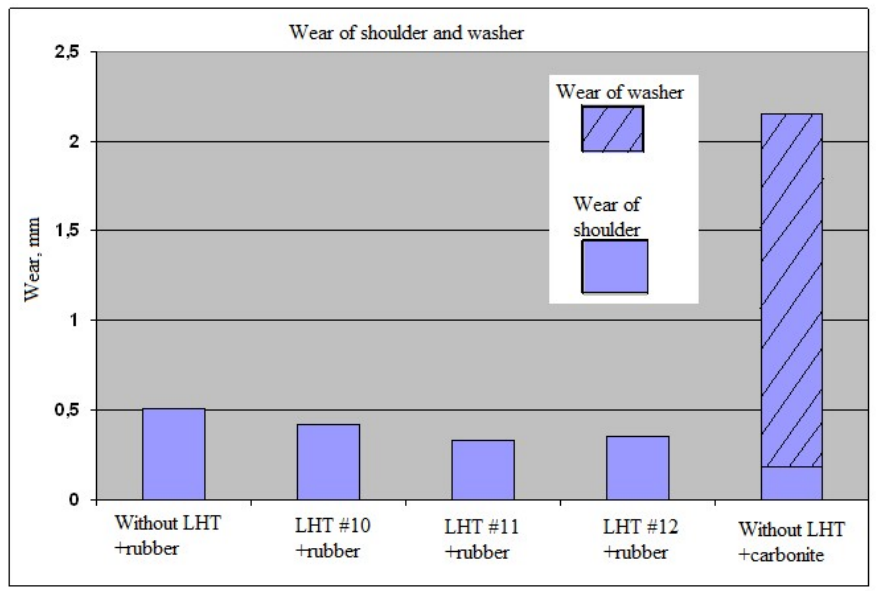

Fig.7. Comparison of cumulative wear of two variants of axial bearings: with rubber washers and with carbonite washers.

Cumulative wear of axial bearing quenched collar-rubber is significantly lower than this of axial rubber non-quenched collar--carbonite. Sample \#11 has the lowest wear, which is also characterized with optimum distribution of internal stresses.

\section{Conclusion}

1. Within laser heat treatment of steel-copper pseudo-alloy FeCCu15, in addition to the complete melting zone, the extensive partial melting zone is generated, where melting takes place in the bulks near lowmelting constituent (copper) in initial structure.

2. Averaged microhardness in the surface layer with thickness of $350 \mu \mathrm{m}$ (zones of melting and partial melting) is 750-900 HV and increases with decrease in the depth of hardened zone.

3. Maximum microhardness of $1000 \mathrm{HV}$ is achieved in the zone of quenching from solid state in the bulk of martensite, generated in pearlite colonies of initial steel-copper material.

4. The configuration of treated item together with the LHT parameters influencers on the final result: dimensions and configuration of melting zone and zone of laser impact.

5. Replacement of the friction couple steel-copper pseudo-alloy-carbonite with the friction pair laser hardened pseudo-alloy--rubber attracts attention. At least within bench-scale experiments the washers made of rubber are not worn. More intensive wear occurs on the annular collar. In this case (in the couple with rubber washers) the laser hardening decreases wear of the annular collar by $35 \%$.

6. This work will be continued aiming at extension of the technology application for various materials and full-scale field tests of quenched diffusers as components of oil-extracting centrifugal pump.

\section{References}

Astapchik, S. A., Babushkin, V. B., \& Ivashko, V. S. (1991). Structural and phase transformations in steels and alloys in laser heat treatment. Metal Science and Heat Treatment, 33(2), 87-93. 
Brytan, Z., Dobrzanski, L. A., \& Pakiela, W. (2011). Laser surface alloying of sintered stainless steels with SiC powder. Journal of Achievements in Materials and Manufacturing Engineering, 47(1), 42-56.

Brytan, Z., Dobrzański, L., \& Pakieła, W. (2011). Sintered stainless steel surface alloyed with Si3N4 powder. Archives of Materials science and Engineering, 50(1), 43-55.

Ivanov, Y. F., Filimonov, S. Y., \& Teresov, A. D. (2011). Alloying the surface of carbon steel with copper by electric explosion of wire and subsequent electron beam treatment. Izvestiya Tomskogo Politekhnicheskogo Universiteta, 318(2), 101-105.

Gilev, V. G., Morozov, E. A., Denisova, A. S., \& Khanov, A. M. (2012). Investigation into microstructure and surface relief within heat treatment of thin-wall cylinder made of powdered steel--copper pseudo-alloy. Izvestiya Samarskogo nauchnogo tsentra, Russian Academy of Science, 5, 1212-1217.

Gilev, V. G., Morozov, E. A., Purtov, I. B., \& Rusin, E. S. (2014). Investigation into microstructure and microhardness of laser melting zones of Ni-resist cast iron, grade ChN16D7GKh. Izvestiya Samarskogo nauchnogo tsentra, Russian Academy of Science, 6, 227-233.

Goia, F. A., \& de Lima, M. S. F. (2011). Surface hardening of an AISI D6 cold work steel using a fiber laser. Journal of ASTM International, 8(2), 1-9.

Grigoryants, G. \& Vasilyev, V.V. (1987) Spatial structure of irradiation of powerful waveguide and fiber lasers for industry. Vestnik of Bauman MGTU, Series “Engineering”, 6, 5-33.

Grigoryants, G. Safonov, A. N., \& Maiorov, V. S., et al. (1987). Distribution of residual stresses on surface of steels hardened by continuous CO2-laser. Metalloved. Term. Obrab., 9, 45-49.

Kannatey-Asibu Jr., E. (2009). Principles of laser materials processing. Wiley, $838 \mathrm{p}$

Kraposhin V. S. (1994). Influence of residual austenite on properties of steels and cast irons after surface melting. Metalloved. Term. Obrab., 2.2-5.

Kraposhin, V. S., Shakhlevich, K. V., \& Vyaz'mina, T. M. (1989). Influence of laser heating on the quantity residual austenite in steels and cast irons. Metal Science and Heat Treatment, 31(10), 745-757.

Kraposhin, V. S., \& Kraposhina I. F. (1989). Influence of parameters of laser irradiation on dimensions of irradiated zones for steel 45. Fiz. Khim. Obrab. Mater., 6, 19-24.

Lisenkov, V. V., Osipov, V. V., \& Platonov, V. V. (2013). Interaction of the radiation of the high-power ytterbiumfiber laser with inhomogeneous dielectric targets. Technical Physics, 58(10), 1469-1475.

Popov, V. (2009). Laser hardening of steels: comparison of fiber and CO2-lasers. Fotonika., 4, 18-21.

Postnikov, V. S., Tomsinskii, V. S., \& Palkina, Yu. V. (1991). Laser hardening of powder steel, grade ZhGr0,5D3L0,3. MiTOM. 11, 32-34.

Babu, P. D., Buvanashekaran, G., \& Balasubramanian, K. R. (2012). Experimental studies on the microstructure and hardness of laser transformation hardening of low alloy steel. Transactions of the Canadian Society for Mechanical Engineering, 36(3), 241-258.

Qiu, F., \& Kujanpää, V. (2011). Transformation hardening of medium-carbon steel with a fiber laser: the influence of laser power and laser power density. Mechanics, 17(3), 318-323.

Safonov, A. N. (1996). Structure and microhardness of the surface layers of iron-carbon alloys after laser heat treatment. Metal science and heat treatment, 38(2), 68-74.

Shiue, R. K., \& Chen, C. (1992). Laser transformation hardening of tempered 4340 steel. Metallurgical Transactions A, 23(1), 163-170.

Tolochko N. K. (1995). Application of lasers in powder metallurgy. Fiz. Khim. Obrab. Mater., 1, 94- 98.

Turichin, G. A., Zemlyakov, E. V., Pozdeeva, E. Y., Tuominen, J., \& Vuoristo, P. (2012). Technological possibilities of laser cladding with the help of powerful fiber lasers. Metal Science and Heat Treatment, 54(34), 139-144.

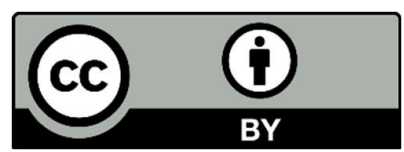

(C) 2020 by the authors; licensee Growing Science, Canada. This is an open access article distributed under the terms and conditions of the Creative Commons Attribution (CC-BY) license (http://creativecommons.org/licenses/by/4.0/). 